\title{
Intracellular storage of mercury and selenium in different marine vertebrates
}

\author{
Marco Nigro ${ }^{1}$, Claudio Leonzio ${ }^{2}$ \\ ${ }^{1}$ Dipartimento di Biomedicina, Università degli Studi di Pisa, Via Volta, 4, I-56126 Pisa, Italy \\ ${ }^{2}$ Dipartimento di Biologia Ambientale, Università degli Studi di Siena, Via delle Cerchia, 3, I-53100 Siena, Italy
}

\begin{abstract}
Intracellular storage and levels of mercury and selenium were studied in the livers of top marine predators belonging to different vertebrate taxa. Total mercury levels showed very important interspecific variations, ranging from $2.6 \mathrm{\mu g} \mathrm{g}^{-1}$ ln tuna and swordfish to several thousand $\mu \mathrm{g} \mathrm{g}^{-1}$ (dry weight) in bottle-nosed and Risso's dolphins. However, methylmercury was less variable, ranging from 1 to $174 \mu \mathrm{g} \mathrm{g}^{-1}$ (dry weight). The ratio between $\mathrm{Hg}$ and Se levels was close to equimolarity in marine mammals and cormorants, but a large excess of selenium in relation to mercury was observed in fish. Electron microscopy and $\mathrm{x}$-ray microanalysis revealed mineral granules consisting of clustered crystalline particles in toothed cetaceans, sea lions and cormorants but not in tuna and swordfish. Granules containing mercury and selenium were mainly located in the cytoplasm of macrophages. These results suggest that the biosynthesis of mineral granules containing mercury and selenium in top marine predators is a common feature among these animals and that the existence of elmination pathways for the excretion of organic mercury might influence the amount of mercury and selenium stored as mineral granules in a particular species.
\end{abstract}

KEY WORDS: Mercury selenide Mercury - Selenium X-ray microanalysis - Marine top predators Mercury detoxication

\section{INTRODUCTION}

Due to its long persistence and high mobility in the marine ecosystem, mercury shows an age-related accumulation and a strong biomagnification in the food web (Bryan 1979, 1984). Numerous studies have demonstrated that both inorganic and organic mercury (mainly methylmercury) occur in marine vertebrates. However, total mercury levels, as well as the relative proportions of its organic and inorganic forms, vary largely according to the trophic level, tissue analyzed and zoological group (see Thomson 1990 for a review).

Mercury in fish occurs almost completely in the organic form (generally $>80 \%$ ) and seldom exceeds $1 \mu \mathrm{g} \mathrm{g}^{-1}$ (wet weight) (Cappon \& Smith 1982). However, in liver tissue of fish-eating marine mammals and seabirds, methylmerrury usually constitutes a very small proportion $(<10 \%)$ of the total mercury concentrations (e.g. Smith \& Armstrong 1978, Gaskin et al. 1979, Falconer et al. 1983, Itano et al. 1984). This reduction in the relative proportion of organic mercury passing from prey to predator has been considered as evidence for a biotransformation process in which methylmercury is degraded into less toxic inorganic storage forms (Buhler et al. 1975, Kari \& Kauranen 1978, Smith \& Armstrong 1978, Reijnders 1980, Thomson \& Furness 1989).

In the livers of some marine mammals, selenium and mercury concentrations have often been found to be present in a 1:1 molar ratio (e.g. Koeman et al. 1973, 1975, Itano et al. 1984, Muir et al. 1988, Leonzio et al. 1992). On the basis of this observation, the interaction with selenium has been supposed to account for the protective effect of this metalloid against mercury toxicity (see Pellettier 1986, Cuvin-Aralar \& Furness 1991 for reviews). Although numerous studies have dealt with analytical determinations, data on the combined intracellular storage of mercury and selenium have been obtained only in cetaceans. Martoja \& Viale (1977) first reported the presence of mineral granules composed of mercury selenide in the livers 
of Cuvier's dolphins. Successively, similar granules were described in the striped dolphin and the role of macrophages in mercury selenide (H.gSe) biomineralization hypothesized (Nigro 1994). More recently, $\mathrm{HgSe}$ was also reported in the respiratory system of bottle-nosed dolphins and short-finned pilot whales, where it was associated with soot particles (Rawson et al. 1995)

The aim of this paper is to improve the knowledge of the intracellular storage of mercury and selenium in marine vertebrates and to verify if the biomineralization is a characteristic of toothed cetaceans exclusively or shared with other species subjected to a high $\mathrm{Hg}$ dietary intake. To achieve this goal, a comparative study using transmission electron microscopy and $\mathrm{x}$-ray microanalysis was done on the livers of top predators belonging to different taxa of marine vertebrates.

\section{MATERIALS AND METHODS}

Samplings. No animal was deliberately killed for this research, all liver samples were obtained from mammals and birds that died of natural causes or from fish that were caught commercially. Liver samples of Risso's Grampus griseus and bottle-nosed dolphin Tursiops truncatus were obtained from cetaceans stranded along Italian coasts (in the framework of the activity of the Italian Center for the Study of Cetaceans). Sea lion Otaria byronia livers were obtained from the colony of Mar del Plata, Argentina, in the framework of a EU research cooperation between Italy and Argentina. Cormorant Phalacrocorax carbo liver samples were provided by the National Institute for Wildlife Biology, Bologna, Italy, and were collected in the Po delta, Italy. Swordfish Xiphias gladius and tuna Thunnus thynnus liver samples were obtained from fishermen of Ustica and Favignana islands (southern Tyrrhenian Sea) respectively.

Chemical analysis. Liver samples were put in plastic bags and stored at $-20^{\circ} \mathrm{C}$ prior to processing for chemical analysis. Total mercury was assayed in $0.1 \mathrm{~g}$ aliquots of freeze-dried tissue samples after digestion in a Teflon bomb for $9 \mathrm{~h}$ at $110^{\circ} \mathrm{C}$ with $2.0 \mathrm{ml}$ of nitric acid (Stoeppler \& Backaus 1978). The solution was analyzed by a cold vapor atomic absorption spectrophotometer with a Perkın-Elmer Model 2280 apparatus.

Methylmercury was analyzed by gas chromatography following the method of Horvat et al. (1990).
Light and electron microscopy. Samples were preserved in buffered formalin, post-fixed in osmium tetroxide, dehydrated in an ascending ethanol series, exchanged in propylene oxide and embedded in EponAraldite. Liver samples were cut on a LKB ultratome III ultramicrotome, using glass or diamond knives. Semithin sections (1. $\mu \mathrm{m}$ thick) were stained with toluidine blue and used for light microscope observations. The relative abundance of mercury selenide in the liver of the species studied was qualitatively estimated in semi-thin sections observed with the $100 \times$ objective. Thin sections were mounted on carbon-formvar coated copper grids and double stained with saturated aqueous uranyl acetate for ultrastructural examinations. Some unosmicated liver sections underwent a proteolytic treatment with $0.5 \%$ aqueous pronase solution at $37^{\circ} \mathrm{C}$ for 3,6 and $9 \mathrm{~h}$ before staining. Post fixation and staining were omitted for $\mathrm{x}$-ray and electron diffraction analysis.

All samples were examined with a Philips M-400 electron microscope equipped with an EDAX x-ray detector and multichannel analyzer, operating at $120 \mathrm{kV}$.

Quantitative $x$-ray microanalysis was done comparing the relative intensity of the Se K $\alpha$ and $\mathrm{HgL} \alpha$ peaks (peak - background) in the sample spectra with that obtained from a standard made of finely powdered commercial mercury selenide (Strem chemicals) dispersed onto a copper specimen grid (see 'Results').

\section{RESULTS}

The concentrations of total mercury, methylmercury and selenium in the liver samples are reported in Table 1. Total Hg level varied widely among the species investigated ${ }_{i}$ the highest value (in toothed cetaceans) being 4 orders of magnitude higher than the lowest one (fish) (Table 1). Methylmercury varied between 1 and $174 \mathrm{\mu g} \mathrm{g}^{-1}$ (Table 1). Mercury and sele-
Table 1 Total mercury, methylmercury and selenium levels ( $\mu \mathrm{g} \mathrm{g}^{-1}$ dry weight) and selenium:mercury molar ratio in the liver of specimens studied by electron microscopy

\begin{tabular}{|lrcrc|}
\hline Species & Total mercury & $\begin{array}{c}\text { Methyl- } \\
\text { mercury }\end{array}$ & Selenium & $\begin{array}{c}\text { Molar ratio } \\
\text { Se:Hg }\end{array}$ \\
\hline Mammals & & & & \\
Bottle-nosed dolphin & 13270 & 174 & 4330 & 0.83 \\
Risso's dolphin & 3828 & 53 & 1413 & 0.93 \\
Sea lion & 891 & 20 & 324 & 0.92 \\
Birds & 131 & 18 & 55 & 1.06 \\
Cormorant & & & & \\
Fish & 2.6 & 1 & 10 & 97.3 \\
Tund & 3.2 & 1 & 19 & 15.03 \\
Swordfish & & & & \\
\hline
\end{tabular}




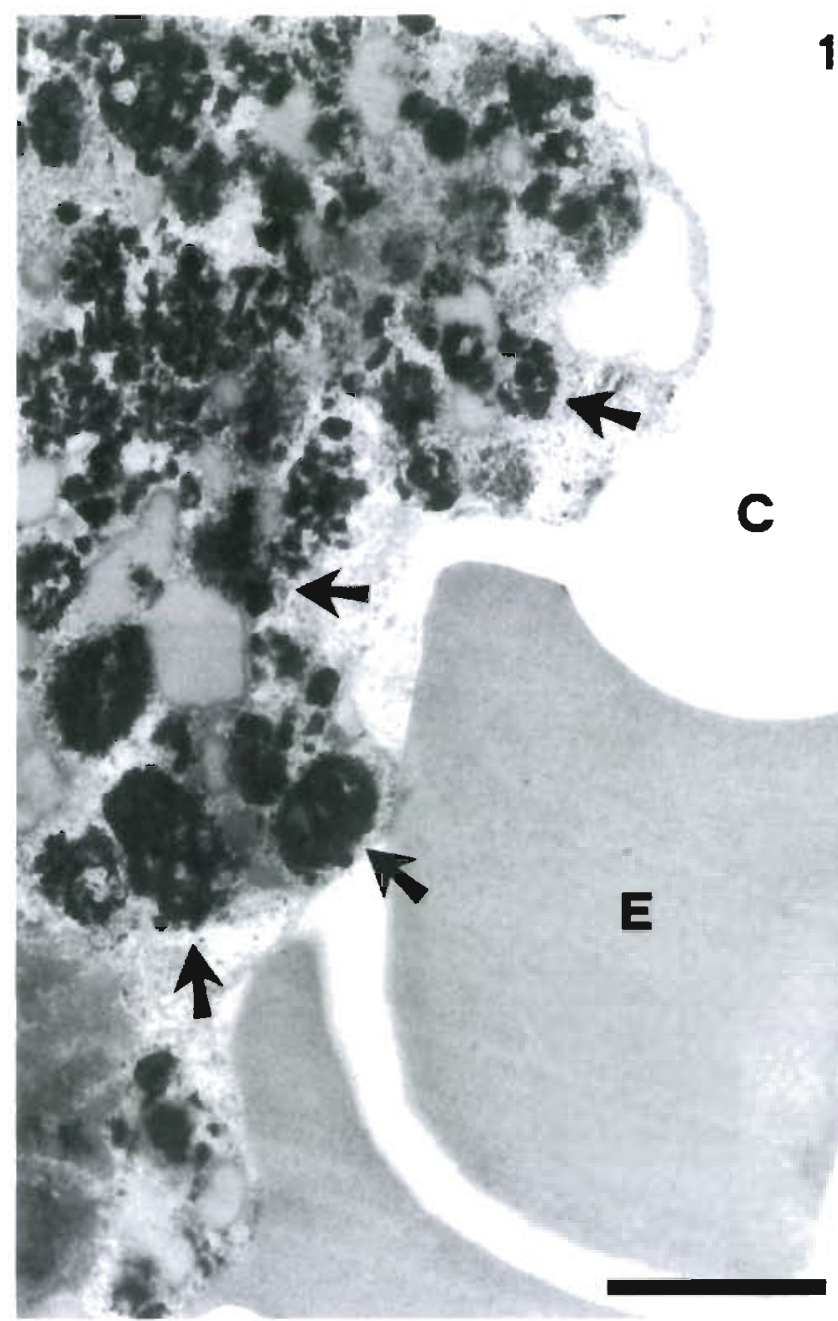

12

2

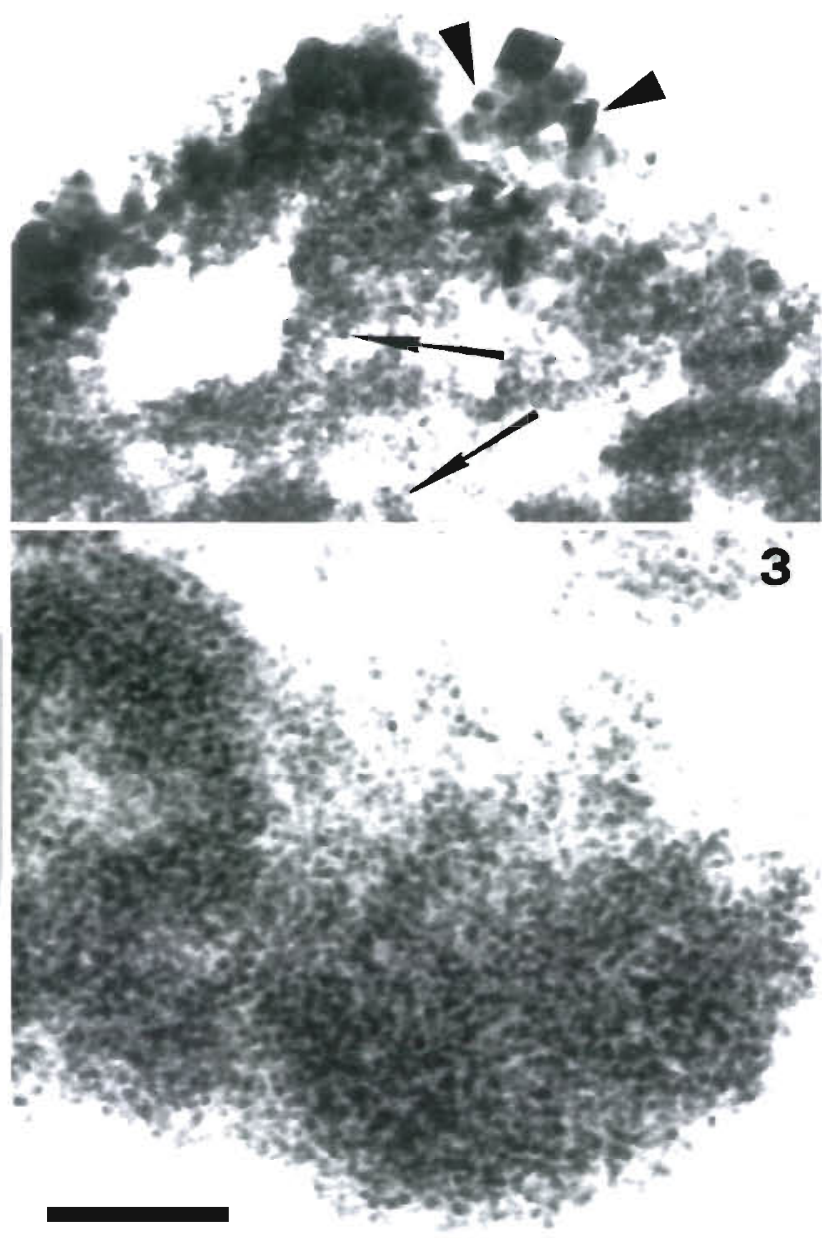

Figs. 1 to 3. Ultrastructure of mammal livers. Fig. 1. Grampus griseus (Risso's dolphin). Liver (HgSe) granules (arrows) in a macrophage adjacent to a capillary lumen (C). E: erythrocytes; scale bar $=2.5 \mu \mathrm{m}$. Fig. 2. Tursiops truncatus (bottle-nosed dolphin). Liver granules composed of tiny spherical particles (arrows) and larger polygonal crystals (arrow heads) ciustered together; scale bar $=0.1 \mu \mathrm{m}$. Fig. 3. Otaria byronia (sea lion). Liver granules composed exclusively of spherical particles; $\mathrm{scale}$ bar $=0.1 \mu \mathrm{m}$

nium occurred in a 1:1 molar ratio in marine mammals and in cormorants, whereas a large excess of selenium was observed in tuna and swordfish (Table 1).

The ultrastructural investigations done on liver sections revealed irregularly shaped dense granules in bottle-nosed and Risso's dolphins, sea lions and cor- morants (Figs. 1 to 3 ), but not in tuna and swordfish. Granules were very abundant in both odontocetes and much less numerous in sea lions and cormorants (Table 2). Granules were most frequently observed distributed along the sinusoids or in the connective tissue surrounding blood vessels (Fig. 1). In high magnification

Table 2. Relative abundance (arbitrary units) and quantitative $x$-ray microanalysis of liver granules in marine vertebrates. $\mathrm{SeK} / \mathrm{HgL}$. mean ratio ( $\pm \mathrm{SD}$ ) of Se Ka and $\mathrm{HgL} \alpha$ peak intensities (peak - background) in the granules. Se/Hg: atomic ratio of selenium and mercury in the granule. $n$ : number of granules analyzed by $x$-ray microanalysis

\begin{tabular}{|c|c|c|c|c|c|c|}
\hline & $\begin{array}{c}\text { Standard } \\
\text { HgSe }\end{array}$ & $\begin{array}{l}\text { Bottle-nosed } \\
\text { dolphin }\end{array}$ & $\begin{array}{l}\text { Risso's } \\
\text { dolphin }\end{array}$ & Sea lion & Cormorant & $\begin{array}{c}\text { Cormorant } \\
\text { pronase }\end{array}$ \\
\hline Abundance & - & +++++ & +++ & ++ & + & + \\
\hline $\mathrm{Se} \mathrm{K} / \mathrm{Hg} \mathrm{L}$ & $0.75 \pm 0.01$ & $0.77 \pm 0.03$ & $0.73 \pm 0.05$ & $0.84 \pm 0.13$ & $\overline{0} .4 \mathrm{i} \pm \bar{U} \cdot \bar{u} \hat{s}$ & $0.47+0.03$ \\
\hline $\mathrm{Se} / \mathrm{Hg}$ & 1.00 & $1.04 \pm 0.04$ & $0.98 \pm 0.06$ & $1.13 \pm 0.17$ & $0.6 \pm 0.06$ & $0.64 \pm 0.04$ \\
\hline$n$ & 5 & 4 & 4 & 5 & 4 & 3 \\
\hline
\end{tabular}


electronmicrographs, delphinid granules were seen to be composed of tightly clustered spherical particles measuring approximately $15 \mathrm{~nm}$ in diameter and larger polygonal particles (of 70 to $80 \mathrm{~nm}$ ) with well-defined shapes (Fig. 2). In sea lions and cormorants (Fig. 3), granules consisted only of spherical particles of about $15 \mathrm{~nm}$.

Liver granules produced electron diffraction patterns consisting of continuous rings and superimposed discrete spots in the bottle-nosed and Risso's dolphins (Fig. 4). This finding, along with the above-reported ultrastructural data, suggests that 2 types of crystalline particles occurred in the liver granules of toothed cetaceans, namely the tiny spherical ones and the larger euhedral crystals. On the other hand, diffraction patterns consisting only of continuous rings were observed in sea lions and cormorants (data not shown), suggesting a structure made of only randomly oriented micro crystallites. In all the species investigated, the diffraction parameters were similar to those of mercury selenide (tiemannite).

Mercury and selenium were the only elements detected in granules by the x-ray microanalysis in the transmission electron microscope (Fig. 5). The relative intensities of the $\mathrm{HgL} \alpha$ and $\operatorname{SeK} \alpha$ peaks (as peak areas) in the spectra of liver granules were calculated and compared with values obtained from the HgSe standard. Since the proportion of mercury and selenium atoms in the standard was $1: 1$ (stoichiometric value), the $\mathrm{Hg}$ :Se ratio in the liver granules was calculated according to the following proportion:

\section{Se:Hg =}

(SeKa:HgL $\alpha$ in the sample):(SeK: $\alpha H g L \alpha$ in the standard).

The results (Table 2) indicate that the Se:Hg ratios in the granules of Risso's dolphin (0.98 \pm 0.06$)$, bottlenosed dolphin $(1.04 \pm 0.04)$, and sea lion (1.13 \pm 0.17$)$ were very close to the stoichiometric value. The Se:Hg

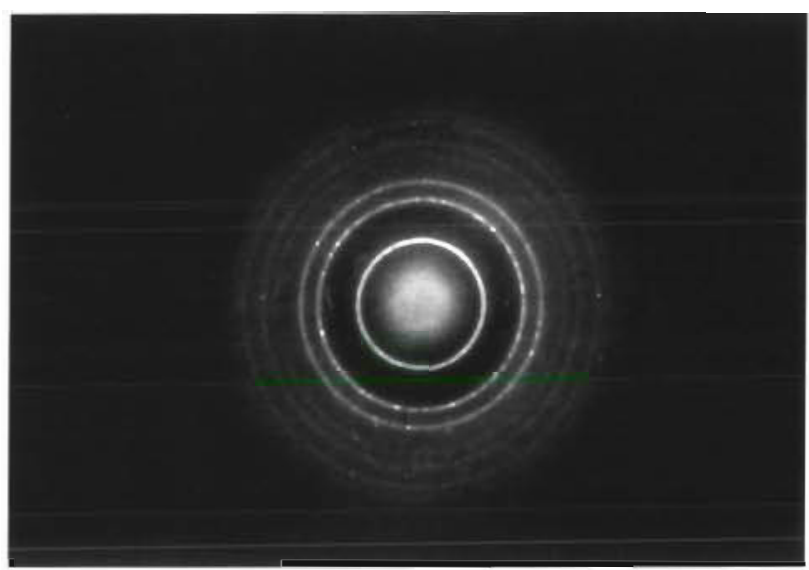

Fig. 4. Grampus griseus (Risso's dolphin). Electron diffraction patterns produced by liver granules, showing continuous rings and superimposed discrete spots
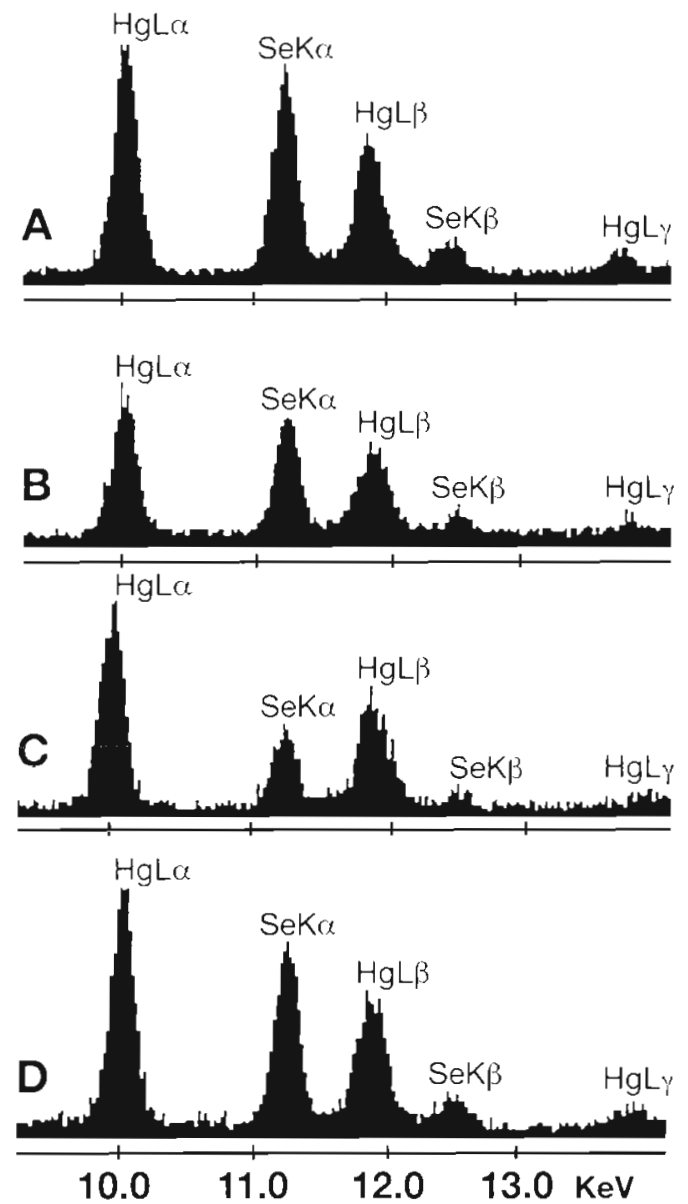

Fig. 5. Part of the x-ray spectrum of the liver granules in different marine vertebrates showing the $\mathrm{HgL}$ and SeK peaks. (A) Bottle-nosed dolphin; (B) sea lion; (C) cormorant; (D) HgSe standard. Vertical scale: x-ray counts; horizontal scale: $x$-ray energy

ratio obtained for the cormorant $(0.6 \pm 0.06)$ was significantly lower, indicating an excess of $\mathrm{Hg}$ with respect to Se (Table 2). As a working hypothesis, we consider that the excess $\mathrm{Hg}$ may be bonded to sulfur substituting for selenium in the mineral structure of the granule, or to any SH-rich protein associated with the granules. Sulfur was not detected by the $x$-ray microanalysis (resolution $150 \mathrm{eV}$ ) due to overlapping of the SK peak (2.3 keV) with the $\mathrm{HgM}$ peak (2.2 keV) (not shown in Fig. 5). To verify the presence of proteins associated with the granules, some sections underwent proteolytic treatment. After incubation with aqueous pronase solution no change in fine morphology (data not shown) or quantitative composition of the granules (Table 2) was observed. These results suggest that the excess mercury in the cormorant granules was probably bonded to inorganic sulfur as part of their crystalline structure and isomorphically substituting for selenium, rather than to SH-groups of proteins. 


\section{DISCUSSION}

Since all the species investigated lived far from focal man-made sources of pollution (with the exception of the cormorant), their mercury and selenium levels should be natural. Total mercury concentration in the liver varied widely, the highest values (measured in odontocetes) being up to 4 orders of magnitude higher than the lowest ones (in pelagic predatory fish). Similarly, the proportion of methylmercury was highly variable among species investigated, being 1 to $2 \%$ of total $\mathrm{Hg}$ in marine mammals, about $13 \%$ in cormorants and more than $30 \%$ in tuna and swordfish. Differences in total mercury concentrations and the relative proportions of organic and inorganic forms in the livers of marine vertebrates are considered to be the consequence of some interacting factors, namely mercury dietary intake, elimination and detoxication/storage (Thomson \& Furness 1989, André et al. 1991). All the study species occupy a terminal position in the marine food web, thus they may be reasonably considered similar with reference to their methylmercury dietary intake. Differences in methylmercury elimination capacity and/or age related storage of detoxified forms may therefore account for the observed interspecific variability in $\mathrm{Hg}$ concentrations.

Demethylation, namely the transformation of organic mercury into the less toxic inorganic form, is believed to occur in those marine mammals and birds which tend to accumulate high levels of prevalently inorganic mercury (e.g. Smith \& Armstrong 1978, Gaskin et al. 1979, Falconer et al. 1983, Itano el al. 1984). The very high mercury concentration in some fish-eating marine vertebrates raises the question of how they avoid toxic effects. In many papers the chemical interaction between mercury and selenium has been indicated as one of the possible mechanisms leading to mercury detoxication (see Pellettier 1986, Cuvin-Aralar \& Furness 1991 for reviews). This conclusion was based on the observation that mercury and selenium levels are often correlated in an equimolar ratio, in the liver of marine mammals (e.g. Koeman et al. 1973, 1975, Itano et al. 1984, Hansen 1990, Muir al. 1988, Leonzio et al. 1992). However, the only direct evidence of the occurrence of a non-toxic product of mercury and selenium interaction. has concerned toothed cetaceans. In these organisms, insoluble mineral granules composed of mercury selenide (tiemannite) were first described by Martoja \& Viale (1977) in the liver of the Cuvier dolphin. Successively, Nigro (1994) reported similar granules in the striped dolphin and hypothesized that mercury selenide prerinitation mainly occurs in macrophage eterophagosomes. More recently Rawson et al. (1995) found $\mathrm{HgSe}$ in both the liver and in the respiratory system of the bottle-nosed dolphin and short-finned pilot whale and reported HgSe in the lung and hilar lymph nodes to be associated with soot particles. Martoja \& Berry (1980) supposed that tiemannite was the product of a process of biosynthesis and represented the final stage of methylmercury degradation. They also suggested that selenium was directly involved in the demethylation process and concluded that the synthesis of HgSe could be expected in species showing a 1:1 molar ratio of mercury and selenium.

The results of the present study support the conclusions of Martoja \& Berry (1980). In fact, the occurrence of mineral granules containing $\mathrm{Hg}$ and $\mathrm{Se}$ was observed in 2 species of Dolphinidae, namely the bottlenosed dolphin and Risso's dolphin. However, it was not limited to toothed cetaceans only, as it was also observed in sea lions and cormorants. In all these species, the presence of mineral granules was accompanied by a $\mathrm{Hg}$ :Se molar ratio close to 1 and a low percentage of organic mercury.

As an alternative to biosynthesis, mineral granules containing mercury and selenium may form as a result of the high affinity of these 2 elements, without any biochemical processes. This hypothesis is not supported by the finding of relatively high mercury and selenium concentrations in baleen whales stranded along the Mediterranean coasts. In these whales in fact, no trace of mineralized forms of mercury or selenium storage could be found ( $M$. Nigro unpubl. obs.), suggesting the occurrence of other unknown forms of detoxication/storage as an alternative to biomineralization.

Although the paucity of data does not permit wide generalizations, the differences in the abundance of mercury selenide granules observed in the species investigated appeared to be mainly related to mercury excretion capacity and detoxication/storage. In dolphins, mineral granules were very abundant and the half-life of mercury was estimated to be $1000 \mathrm{~d}$, suggesting a very limited excretion capacity (Itano \& Kawai 1986). Moreover, the mercury dietary intake for dolphins living in the Mediterranean Sea was estimated at about $1 \mathrm{mg} \mathrm{d}^{-1}$ (Nigro \& Leonzio 1993). Such a high mercury intake accompanied by negligible excretion might have forced toothed cetaceans to develop, over an evolutionary time scale, a very efficient process of mercury detoxication and storage. Similarly, dolphin lymphocytes have been demonstrated to be much more resistant to both the cytotoxic and genotoxic effects of methylmercury than rat or human cells after in vitro exposure to the toxic pollutant (Betti \& Nigro 1996).

Pinnipeds, like dolphins, can degrade methylmercury, accumulating mainly inorganic $\mathrm{Hg}$ in the liver (Buhler et al. 1975, Kari \& Kauranen 1978, Smith \& Armstrong 1978, Reijnders 1980). Our data show that at least part of this form of mercury is stored as mer- 
cury selenide granules. However, unlike toothed cetaceans, pinnipeds possess efficient methylmercury excretion capacity through the fur (Wenzel et al. 1993) by virtue of the strong binding between organic mercury and sulfhydryl groups of keratins (Crewther et al. 1965). In addition, seals are known to detoxify mercury by binding it to metallothioneins (Olafson \& Thomson 1974. Hamanaka et al. 1982. Mochizuchi et al. 1985 , Tohyama et al. 1986). All these features might account for the lower Hg level usually found in pinnipeds with respect to dolphins (see Thomson 1990) and the scarcity of liver granules found in the present study.

Birds eliminate methylmercury via the feathers (e.g. Honda et al. 1986, Furness 1993). This has been demonstrated to be an important mercury excretion pathway in these organisms (Braune \& Gaskin 1987). Seabirds with slow moult cycles, such as albatrosses, have a restricted elimination capacity (Thomson \& Furness 1989). According to Thomson \& Furness (1989) these birds solve the problem by converting a proportion of organic mercury into an inorganic storage, performing a toxicologically less demanding alternative to the accumulation of methylmercury. The specimens of cormorant studied showed high total mercury levels and a low ratio of organic to inorganic mercury, which are typical features of birds with limited mercury excretion capacity. The fact that liver granules containing mercury and selenium were found in the study species demonstrates that the bromineralization, as a non-toxic form of $\mathrm{Hg}$ and Se storage, is not restricted to marine mammals but also occurs in seabirds. It could be hypothesized that mineral granules are formed if elimination through the feathers cannot match the dietary intake of mercury.

Tuna and swordfish occupy a similar trophic level to dolphins and consequently have a similar mercury dietary intake. Nevertheless they have the lowest total mercury concentrations, the highest proportion of organic mercury and lack mineral granules. In practice, the biomagnification factor with respect to mercury levels in prey is 500 for delphinids and 30 for predatory pelagic fish (Nigro \& Leonzio 1993). Physiological differences between fish and marine mammals may partly explain their different capacity to store mercury. For instance, fish have gills that maintain a constant and direct contact between the blood and sea water when large quantities of methylmercury are ingested with the diet, as occurs in large pelagic fish, the load may reach concentrations of more than $100 \mathrm{\mu g} \mathrm{ml^{-1 }}$ whereas mercury levels in the water range from 5 to $25 \times 10^{-7} \mu \mathrm{g} \mathrm{ml}$ - $^{-1}$ (Copin-Montegut et al. 1984) This enormous difference suggests that mercury exchange would easily occur through the gradient blood-seawater, giving fish a further efficient elimination system, beside renal and bile excretion.
In conclusion, we can say that ultimate marine consumers, particularly fish-eating animals, have the common task of reducing methylmercury toxicity as a consequence of their high dietary intake. The processes are fundamentally direct elimination of methylmercury and/or biotransformation and bioaccumulation of a non-toxic product. The mechanisms of the latter process are largely unknown, occurring mainly in feral animals, such as dolphins, which can be investigated using exclusively non-destructive approaches. More studies are needed to clarify both the physiological mechanisms of mercury and selenium biomineralization and the factors influencing its occurrence among marine organisms.

Acknowledgements. The authors are grateful to Dr U. Agrimi and Dr A. Massi for furnishing respectively toothed cetaceans and cormorant liver samples. Prof. M. Mellini for his help in interpretation of mineralogic data and Prof. S. Bonotto tor instructive comments on the manuscript. This is publication no. 53 of the Italian 'Centro Studi Cetacei'

\section{LITERATURE CITED}

André JM, Boudou A, Ribeyre F (1991) Mercury accumulation in delphinidae. Wat Air Soil Pollut 56:187-203

Betti C, Nigro M (1996) The comet assay for the evaluation of the genetic hazard of pollutants in cetaceans. Preliminary results on the genotoxic effects of methyl mercury on the bottle-nosed dolphin (Tursiops truncatus) Iymphocytes in vitro. Mar Pollut Bull (in press)

Braune BM, Gaskin DE (1987) Mercury levels in Bonaparte's gull (Larus phlladelphia) during autumn moult in the Quoddy region, New Brunswick, Canada. Arch Environ Contam Toxicol 16:539-549

Bryan GW (1979) Bioaccumulation of marine pollutants. Phil Trans R Soc Lond B 286:483-505

Bryan GW (1984) Pollution due to heavy metals and their compounds. In: Kinne $O$ (ed) Marine ecology. Wiley; Chichester, p 1289-1431

Buhler DR, Claeys RR, Mate BR (1975) Heavy metals and chlorinated hydrocarbon residues in Californian sea lions (Zalophus californianus). J Fish Res Bd Can 32:2391-2397

Cappon CJ, Smith JC (1982) Chemical form and distribution of mercury and selenium in edible seafood. Bull Environ Contam Toxicol 29:285-289

Copin-Montegut G, Courau PH, Laumond F (1984) Occurrence of mercury in the atmosphere and waters of the Mediterranean. FAO Fisheries Report No. 325 Supplement:51-57

Crewther WG, Fraser RDB, Lennox FG, Lindley H (1965) The chemistry of keratins. Ads Prot Chem 20:191-346

Cuvin-Aralar MLA, Furness R (1991) Mercury and selenium interactions: a review. Ecotoxicol Environ Saf 21:348-364

Falconer RC, Davies IM, Topping G (1983) Trace metals in the common porpoise Phocena phocena. Mar Environ Res 8: 119-127

Furness RW (1993) Birds as monitor of pollutants. In: Furness RW, Greenwood JJD (eds) Birds as monitors of environmental change. Chapman and Hall, London, p 86-143

Gaskin DE, Stonefield KI, Suda P. Frank R (1979) Changes in mercury levels in harbor porpoises (Phocena phocena) 
from the Bay of Fundy (Canada) and adjacent waters during 1969-1977. Arch Environ Contam Toxicol 8:733-762

Hamanaka T, Itoo T, Mishima S (1982) Age-related change and distribution of cadmium and zinc concentration in stellar lion (Eumetopas jubata) from the coast of Hokaido. Japan. Mar Pollut Bull 13:57-61

Hansen JC (1990) Human exposure to metals through consumption of marine foods: a case study of exceptionally high intake among Greenlanders. In: Furness RW, Rainbow PS (eds) Heavy metals in the marine environment. CRC Press, Inc, Boca Raton, p 227-243

Honda K, Nasu T, Tatsukava R (1986) Seasonal changes in mercury accumulation in the black-eared kite, Milvus migrans lineatus. Environ Pollut 42:3325-334

Horvat M, Byrne AR, May K (1990) A modified method for the determination of methylmercury by gaschromatography. Talanta 37:207-212

Itano K, Kawai S (1986) Changes of mercury content and biological half-life of mercury in the struped dolphins. In: Fujiyama $T$ (ed) Studies on the levels of organochlorine compounds and heavy metals in marine organisms. University of Ryukyus, p 49-73

Itano K. Kawal S, Miyazaki N, Tatzukawa R, Fujiyama T (1984) Mercury and selenium leveis in striped dolphins caught off the Pacific coasts of Japan. Agric Biol Chem 48: $1109-1116$

Kari T, Kauranen P (1978) Mercury and selenium contents in seals from fresh and brackish waters in Finland. Bull Environ Contam Toxicol 19:273-280

Koeman JH, Peeters VHM, Koudstaal-Hol CHM, Tjioe PS, De Goeu JJM (1973) Mercury selenium correlation in manine mammals. Nature 246:385-386

Koeman JH, Van de Ven WSM, De Goeu JJM, Tjioe PS, van Haaften JL (1975) Mercury and selenium in marine mammals and birds. Sci Total Environ 3:279-287

Leonzio C. Focardi S, Fossi C (1992) Heavy metals and selenium in stranded dolphins of the northern Tyrrhenian (NW Mediterranean). Sci Total Environ 119:77-84

Martoja R, Berry JP (1980) Identification of tiemannite as a probable product of demethylation of mercury by selenium in cetaceans. Vie Milieu 30:7-10

Martoja R, Viale D (1977) Accumulation de granules de séléniure mercurique dans le foie d'Odontocètes (Mammifères, Cétacés): un mécanisme possible de détoxication du méthylmercure par le sélénium. Cr Hebd Séanc Acad Sci, Paris D 285: 109-112

Mochuzuchi Y, Suzuki KT. Sunaga H, Kobayashi T, Doi R (1985) Separation and characterization of metallothionein

This article was submitted to the editor in two species of seals by high performance liquid chromatography-atomic absorption spectrophotometry. Comp Blochem Physiol 82(C):248-254

Muir DCJ, Wagemann R, Grift NP, Norstrom RJ, Simon M, Lien J (1988) Organochlorine chemical and heavy metal contaminants in white-beaked dolphins (Lagenorynchus albirostris) and pilot whales (Globicephala melaena) from the coast of Newfoundland. Canada. Arch Environ Toxicol $17: 613-628$

Nigro M (1994) Mercury and selenium localization in macrophages of the striped dolphin, Stenella coeruleoalba. J Mar Biol Ass UK 74:975-978

Nigro M, Leonzio C (1993) Mercury selenıde accumulation in dolphins. In: Evans PH (ed) Procecdings 7 th Annual Conference of the European Cetacean Society, Inverness, Scotland, February 1993. Cambridge, p 212-215

Olafson RW, Thomson JAJ (1974) Isolation of heavy metal bınding proteins from marine vertebrates. Mar Biol 28: $83-86$

Pellettier $E$ (1986) Mercury-selenium interactions in aquatic organisms a review: Mar Environ Res 18:111-132

Rawson AJ, Bradley JP, Teetsov A, Rice SB, Haller EM, Patton GW (1995) A role for airborne particulate in high mercury levels of some cetaceans. Ecotoxicol Environ Saf 30:309-314

Reijnders PJH (1980) Organochlorine and heavy metal residues in harbor seals from the Wadden Sea and their possible effects on reproduction. Neth J Sea Res 14:30-65

Smith TG, Armstrong FAJ (1978) Mercury and selenium in ringed and bearded seal tissues from Arctic Canada. Arctic 31:75-84

Stoeppler M, Backaus F, (1978) Pretreatment studies with biological and environmental materials, I. System of pressurized multisample decomposition. Fresenius Z Anal Chem 231:116-200

Thomson DR (1990) Metal levels in marine vertebrates. In: Furness RW, Rainbow PS (eds) Heavy metals in the marine environment. CRC Press, Inc, Boca Raton, p 143-182

Thomson DR, Furness RW (1989) The chemical form of mercury stored in south Atlantic seabirds. Environ Pollut 60:305-317

Tohyama C, Himeno SJ, Watanabe C, Suzuki T, Morita M (1986) The relationship of the increased level of metallothioneins with heavy metals in the tissues of the harbor seal (Foca vitulina). Ecotoxicol Environ Saf 12:85-94

Wenzel C, Adelung D, Kruse H, Wassermann O (1993) Trace metal accumulation in hair and skin of the harbour seal, Phoca vitulina. Mar Pollut Bull 26:152-155

Manuscript first received: September 22, 1995 Revised version accepted: December 11, 1995 